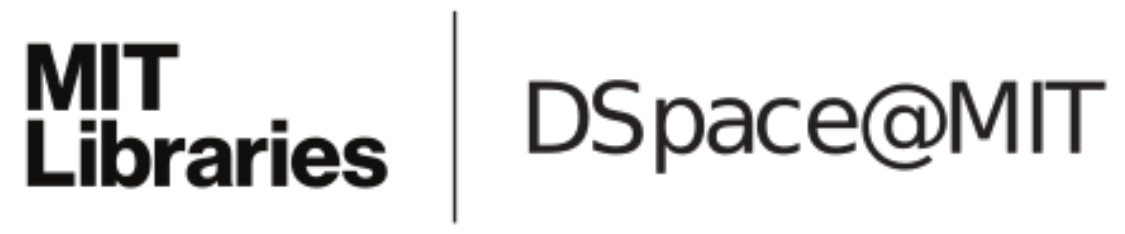

\author{
MIT Open Access Articles
}

Conditional Propositions and Conditional Assertions

The MIT Faculty has made this article openly available. Please share how this access benefits you. Your story matters.

Citation: Stalnaker, Robert. "Conditional Propositions and Conditional Assertions." Epistemic modality, edited by Andy Egan and Brian Weatherson. Oxford University Press, 2011: 227-247 (C) 2011 The Author.

As Published: http://dx.doi.org/10.1093/acprof:oso/9780199591596.003.0008

Publisher: Oxford University Press

Persistent URL: https://hdl.handle.net/1721.1/123486

Version: Author's final manuscript: final author's manuscript post peer review, without publisher's formatting or copy editing

Terms of use: Creative Commons Attribution-Noncommercial-Share Alike 


\title{
CONDITIONAL PROPOSITIONS AND CONDITIONAL ASSERTIONS
}

\author{
Robert Stalnaker
}

One standard way of approaching the problem of analyzing conditional sentences begins with the assumption that a sentence of this kind expresses a proposition that is a function of the propositions expressed by its component parts (plus, perhaps, some features of the context in which the sentence is uttered). The task is to characterize this function. But there is also a long tradition according to which conditional sentences - at least some conditional sentences - are used to perform a special kind of speech act. A conditional assertion is not a standard kind of speech act (assertion) with a distinctive kind of content (a conditional proposition), but rather a distinctive kind of speech act that involves just the two propositions, the ones expressed by the antecedent and the consequent. There has been considerable controversy about which of these two strategies for explaining conditionals is better.

There is a second controversial issue that interacts with this one: conditional sentences have traditionally been divided into two categories, usually labeled "subjunctive" and "indicative" even though it has long been recognized that while there is a clear grammatical contrast between the two kinds of conditionals, the difference is not a simple matter of grammatical mood. The issue concerns the relationship between the conditionals of the two kinds. Some theorists have treated the problem of analyzing indicative and subjunctive conditionals as separate problems, each to be treated on its own terms. Others have sought some kind of unified analysis. It is clear that the two kinds of conditionals have much in common, but also clear that there are semantic differences between them, since there are minimal pairs, differing only in that one is "subjunctive" and the other "indicative" that seem, intuitively to say quite different things. ${ }^{1}$ So while it is uncontroversial that the contrast between the two kinds of conditionals is not a simple and superficial one, there remains a question whether one can explain the semantic and pragmatic differences within a unified theory of conditionals, or whether one should treat the two kinds of "ifs" as different concepts that happen to be expressed by the same word. The issue about whether conditionals express propositions interacts with the question whether we can give a unified account of the two kinds of conditionals, since the considerations favoring the propositional analysis of conditionals are much stronger in the case of subjunctive conditionals, while the considerations favoring the conditional assertion account are much stronger in the case of indicative conditionals.

Some philosophers - David Lewis and Frank Jackson, for example - make no attempt to give a unified account that covers both kinds of conditionals, but still support the hypothesis that

${ }^{1}$ By a semantic difference, I mean here a difference in the assertive content that utterances of the contrasting conditional sentences would have in a similar situation. This is compatible with the hypothesis that the abstract semantics for the two conditionals is the same, but that the difference in content is explained by a difference in contextual determinants relative to which the contrasting kinds of conditionals are interpreted. 
indicative conditionals have truth conditions. Lewis gave the following reason for this decision:

I have no conclusive objection to the hypothesis that indicative conditionals are non-truth-valued sentences, governed by a special rule of assertability. . . . I have an inconclusive objection, however: the hypothesis requires too much of a fresh start. It burdens us with too much work still to be done, and wastes too much that has been done already. ... . We think we know how the truth conditions for compound sentences of various kinds are determined by the truth conditions of constituent subsentences, but this knowledge would be useless if any of those subsentences lacked truth conditions. Either we need new semantic rules for many familiar connectives and operators when applied to indicative conditionals perhaps rules of truth, perhaps special rules of assertability like the rule for conditionals themselves - or else we need to explain away all seeming examples of compound sentences with conditional constituents. ${ }^{2}$

Lewis's methodological concern might be generalized. It is not only that if we treat indicative conditionals as truth-conditional, we can draw on the resources of compositional semantics to explain the embedding of conditionals in other constructions, it is also that we can draw on standing accounts of speech acts, such as assertion, and of propositional attitudes such as belief, and epistemic states such as knowledge to explain the assertion of, belief in, and knowledge of conditionals. Speech acts and propositional attitudes are standardly factored into content and force, or content and kind of attitude. By treating a conditional as a distinctive kind of content, one avoids the problem of giving an account of distinctive kinds of conditional force, and distinctive conditional mental states.

But these methodological considerations cut both ways. While there are some complex constructions with indicative conditionals as constituents, the embedding possibilities seem, intuitively, to be highly constrained. For example, simple disjunctions of indicative conditionals with different antecedents and conditionals with conditional antecedents are difficult to make sense of. The proponent of a non-truth-conditional account needs to explain what embeddings there are, but the proponent of a truth-conditional account must explain why embedded conditionals don't seem to be interpretable in full generality. And while the truth-functional analysis of indicative conditionals favored by Lewis, Jackson and Paul Grice can make sense of negations and disjunctions with conditionals parts, it is in those kinds of constructions that the consequences of the truth-functional analysis are most difficult to reconcile with intuitions about examples.

On the speech act and attitude issue: it would be an advantage to reduce the problem of conditional assertion, promise, command, belief, intention, knowledge, and so forth to the single problem of analyzing a kind of content - conditional propositions - that they all share, but on the other hand, it may distort the phenomenon of conditionality to do so. As is often noted,

${ }^{2}$ Lewis (1976). 
conditional bets and questions are not properly understood as bets on or questions about the truth of a conditional proposition, and conditional promises do not seem to be promises to make true a conditional proposition. It may also be that a proper account of belief, intention and knowledge must make room for conditional versions of these attitudes that cannot be reduced to categorical belief, knowledge and intention.

So there are costs and benefits on both sides to be weighed in comparing the truth-conditional and non-truth-conditional accounts of conditionals. My aim in this paper is to try to get clearer about what is at stake in this debate, focusing on the case of indicative conditional assertions. More generally, I hope to get clearer about the relation between speech acts and the propositions and propositional attitudes that are expressed in them. My strategy will be to sketch a specific account of each kind within a common framework, and then to consider exactly how they differ. One of my conclusions will be that while there are real differences between the accounts, they may be less significant than they have seemed.

In section I, I will sketch a conditional assertion account, which will require saying something about how categorical assertion should be understood. In section II I will sketch a non-truth functional propositional account of indicative conditionals, an account that is basically the same as one I proposed some years ago. While this account has problems, it is not so easily refuted as has been suggested. I will respond to some arguments against it, but also say what I think the real problems with the account are. There are tensions, I will suggest, between the roles of public knowledge (or common ground) and of the knowledge and beliefs of individual speakers in determining what is said in indicative conditional statements. I will conclude, in section III, with an example that brings out this tension, and that is a problem for both propositional and conditional assertion accounts.

\section{Conditional speech acts}

W. V. Quine, in an often quoted remark, said that

An affirmation of the form 'if $p$ then q' is commonly felt less as an affirmation of a conditional than as a conditional affirmation of the consequent. If, after we have made such an affirmation, the antecedent turns out true, then we consider ourselves committed to the consequent, and are ready to acknowledge error if it proves false. If on the other hand the antecedent turns out to have been false, our conditional affirmation is as if it had never been made. ${ }^{3}$

G. H. von Wright, in a 1957 article on conditionals, proposed to treat the conditional as a "mode of asserting," and tentatively suggested that conditional sentences do not express propositions: "I shall never speak of a conditional as a proposition which is being asserted, but only of

${ }^{3}$ Quine (1959), 12. 
propositions being asserted conditionally, relative to other propositions.” ${ }^{4}$ J. Mackie characterized a conditional assertion, if $p$, then q, as an assertion of q within the scope of the supposition that p. ${ }^{5}$ But how exactly is the speech act of conditional assertion to be understood?

To better understand what needs to be said to answer this question, it will help to say a little bit about how the speech act of categorical assertion is to be understood. There are two ways of approaching the task of giving an account of a speech act such as assertion, both of which have their roots in J. L. Austin's work on speech acts. Speech acts obviously alter the situation in which they take place, and one might try to explain what it is to make an assertion by saying how it changes, or is intended to change, the context. Alternatively, one might characterize assertions in terms of the way they are assessed. Speech acts are generally assumed to be moves in a rulegoverned institutional practice, and one might focus on the constitutive norms that constrain the practice. A speech act might be successful in the sense that it succeeds in changing the context in the way that assertions are intended to change the context, but still be defective in some way still be an assertion that failed to meet some standard or norm that assertions are supposed to meet. A full account of assertion should include an account of such standards or norms.

David Lewis, in his “Score keeping in a language game,” sketches a framework for answering the first question. He suggested that we think of a conversation as like a game with an evolving score, and of speech acts as moves in the game. A characterization of a speech act of a certain kind will be an account of how the speech act changes the score of the game. My account of

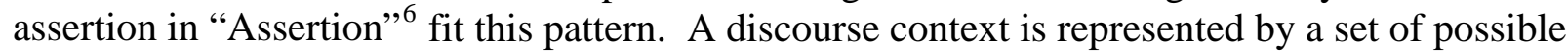
situations - a context set - representing the relevant alternatives, or live options that the conversational participants intend to distinguish between in their speech acts. The essential effect of an assertion is to add the content of the assertion to the information that is henceforth to be presupposed - to eliminate from the context set those possible situations that are incompatible with the content of the assertion. On this account, one might think of an assertion as something like a proposal to change the context set in that way, a proposal that is adopted if it is not rejected by one of the other parties to the conversation.

Different theorists might accept this account of the effect of assertions, but give different answers to the question about how assertions are assessed, and one might distinguish different speech acts in terms of the way they are assessed, even if they change the context in the same way. For example, parties to a conversation might agree to accept certain things that they may not be in a position to assert. ("It's probably going to rain - let's assume that it will." Or lawyers in a court proceeding may agree to stipulate certain facts). This kind of speech act

${ }^{4}$ von Wright (1957), 131.

${ }^{5}$ Mackie (1973).

${ }^{6}$ Chapter 4 of Stalnaker (1999), originally published in 1978. 
changes the context in the same way as an assertion, but may be subject to different norms. ${ }^{7}$

Here are some contrasting answers to the question about the norms of assertion that have been given:

(1)Some claim that the only norm for assertion is truth. That is, an assertion of something false is defective, subject to criticism, but a true assertion achieves all that assertions essentially aim at. This account need not say that a speaker who makes a false assertion is always subject to criticism - she might have had good reason to believe that her action conformed to the norm. And conversely, the account will allow that speakers may be subject to criticism even for true assertions, if they did not have good enough reason to believe that they were true. There are general norms that one should take care, in one's actions, to ensure that one meets the standards that apply to those actions. The claim is that the only specific norm governing assertion is the norm of truth.

(2) Others - most prominently, Timothy Williamson - have argued that successful assertions must meet a higher standard: the speaker represents himself as knowing the content of the assertion, and so the assertion fails of its aim if the speaker does not have this knowledge. ${ }^{8}$ Again, speakers who make assertions without knowledge may not be subject to criticism, should they be justified in believing that they knew the truth of what they asserted, but their assertions will still be defective when the speaker lacks knowledge. ${ }^{9}$

(3) Robert Brandom and others have argued that one who makes an assertion undertakes a commitment to defend the truth of the assertion in response to reasonable challenges - a proposed norm that is weaker in some respects, and stronger in others than the norm of

${ }^{7}$ I don't want to suggest that there is a sharp or deep line between the two kinds of questions about speech acts (how do they change the context, and how are they assessed). If two speech acts are subject to different norms, then they will inevitably change the context in different ways as a result. For example, if knowledge is a mutually recognized norm of assertion, then an assertion that $P$ will normally change the context by making it common ground that the speaker has represented herself as knowing that $P$. But different theorists have emphasized one or the other of these questions, and I think it is useful to their answers as complementary parts of a full account of a speech act.

${ }^{8}$ Williamson (1996) and (2000), ch. 11.

${ }^{9}$ The difference between the truth norm and the knowledge norm is subtle, and some might argue that there is really no difference, given that to meet the norm of truth (together with the general norm that one should have sufficient reason to believe that one is conforming to any specific norm), one must have sufficient reason to believe that one's assertion is true, and that might be hard to distinguish from sufficient reason to believe that one had knowledge. But Williamson argues that there is a difference, and that it is important. 
knowledge. ${ }^{10}$ Thus an assertion by one who is uncertain of the truth of what he asserts, but who is prepared to give arguments, and to withdraw the claim in the face of good counter arguments satisfies this norm, while failing to satisfy the knowledge norm. On the other hand, one who says "I will tell you what I know, but you will just have to take my word for it" may satisfy the knowledge norm, while failing to live up to this one.

(4) A Bayesian might say that assertability is a matter of degree. ${ }^{11}$ The higher the degree of belief that the speaker has in the truth of the content of the assertion, the more asssertable it is. How high is high enough will depend on context - on the balance of the costs of being wrong, and the benefits of getting it right.

Now with those models of what an account of a speech act might look like, how might one explain conditional assertion? First, here is an answer to the first question, paralleling the account of the effect of categorical assertion on the context: First, one adds the content of the antecedent, temporarily, to the context; that is, one sets aside the possibilities in the context set in which the supposition is false. ${ }^{12}$ (What if the supposition is incompatible with the prior context, so that the whole context set is set aside? In this case, just as in the case of a categorical assertion that is incompatible with the prior context, the speech act will be inappropriate unless there is a way to adjust the context to make it compatible with the supposition) Then the content of the consequent is treated like the content of a categorical assertion: one eliminates, from this temporary or derived context those possible situations that are incompatible with the content of the consequent. Finally, one adds back the possibilities that one had set aside.

David Lewis, and other defenders of the material conditional analysis might point out that on this account, the effect of a conditional assertion is exactly the same as the effect of the categorical assertion of the corresponding material conditional. Is this just an example of Lewis's methodological point that a non-truth conditional account will have to do over again work that has already been done? The defender of the conditional assertion analysis will argue that it is not. Even if the effect of a conditional assertion is exactly the same as the effect of a categorical assertion of the corresponding material conditional, that does not mean that the overall account of conditionals is the same on the two accounts. It was, after all, Lewis's point that the material conditional analysis yields an account of the role of conditionals in embedded contexts, while the conditional assertion account (without further supplementation) does not. And it is with embedded conditionals that the material conditional account runs into trouble.

The most striking counterexamples to the material conditional analysis of conditionals are

${ }^{10}$ Brandom(1983).

${ }^{11}$ I don't mean to suggest that anyone who accepts a Bayesian account of belief and degree of belief is committed to any particular line on norms of assertion,

${ }^{12}$ Swanson (2004) argues that we should think of conditional assertions as two different speech acts - an act of supposition followed by an assertion under the scope of the supposition. 
negations of conditionals. My favorite is an argument for the existence of God cited by Dorothy Edgington, and attributed to W. D. Hart: If there is no god, then it is not the case that if I pray, my prayers will be answered. I don't pray; therefore, there is a god. The premisses seem more reasonable than the conclusion, but if the conditional is the material conditional, the argument is valid. ${ }^{13}$ On the conditional assertion account, as Lewis observed, there is no straightforward interpretation of the negation of an indicative conditional, but it is natural to interpret it as a conditional denial. To deny that if I pray, my prayers will be answered is the same as to assert that my prayers will not be answered, conditional on my praying. (In the argument, the negation of the conditional is also embedded in a conditional context, but the conditional assertion account has no problem with conditionals with conditional consequents. "If $A$, then if $B$, then $C$ " is a conditional assertion of $C$ on condition $B$, made in the context of a supposition that $A$.) The defender of the material conditional analysis may try to explain the discrepancy between intuitive judgments about negations of conditionals and what is implied by his analysis by paraphrasing the negative conditional, putting the negation on the consequent (perhaps using some kind of general bracketing device, such as Grice proposed in his defense of the material conditional analysis ${ }^{14}$ ), but to do this is to give up the methodological advantage that Lewis claimed for a truth-conditional account.

Negations of indicative conditionals often seem interpretable, and when they are, are most naturally interpreted as conditionals with the negation on the consequent. In contrast, disjunctions of indicative conditionals (with different antecedents) are hard to make sense of. Suppose I were to say "Either he will win if he carries Ohio, or he will carry Ohio if he wins." If you can make sense of this at all, does it seem to be a tautology (as it is, on the material conditional analysis)?

The conditional assertion account yields no natural interpretation for a disjunction of conditionals with different antecedents (If the antecedents of the disjoined conditionals are the same, then they might naturally be interpreted as an assertion of the disjunction of the consequents, conditional on their common antecedent.) If you find such conditionals intuitively bewildering, this is a point (at least a small point) in favor of the conditional assertion account.

So the conditional assertion account yields the result that the effect of a conditional assertion is the same as the effect of a categorical assertion of a material conditional, but this does not imply that the two accounts are equivalent for just the reason that Lewis emphasized: if conditionals have truth conditions they may be embedded in other truth-conditional contexts. The two accounts may also differ in what they say about how conditional assertions should be assessed. What are the norms of conditional assertion? Each of the alterative accounts of the norms of categorical assertion suggests a natural extension to an account of the norms of conditional assertion. Let me consider them in turn.

\footnotetext{
${ }^{13}$ Edgington (1986), 187

${ }^{14}$ Grice (1989), ch. 4.
} 
(1) If truth is the sole norm of assertion, then the natural extension to conditional assertion would be to say that a conditional assertion is subject to a conditional norm of truth (of the consequent), conditional on the truth of the antecedent. This is the norm suggested by the remark from Quine quoted above. The sense in which the conditional affirmation is "as if it had never been made" in the case where the antecedent is false is that it is then not subject to criticism for violating the norm. On this account, the norm for conditional assertion is, in effect, the same as the norm for a categorical assertion of a material conditional. ${ }^{15}$

(2) If knowledge is the norm for categorical assertion, then it seems reasonable to require that a speaker have conditional knowledge of the consequent, conditional on the truth of the antecedent. But what is conditional knowledge? In the case where a person is unsure whether a condition $A$ is true or false, then it seems reasonable to say that she has knowledge of $B$, conditional on $A$, just in case she has categorical knowledge of the material conditional, ( $A \varepsilon B$ ), so at least in the case where the speaker is uncertain about the truth of the antecedent, the norm will be, in effect, the same as the norm for the categorical assertion of the corresponding material conditional. But what about situations where the speaker knows the antecedent to be false? In this case, she knows the truth of the material conditional, but if we can make sense of conditional knowledge in this kind of situation, then there might be cases where one would satisfy the norm for the categorical assertion of the material conditional, while violating the norm for conditional assertion.

One might be tempted to think that a conditional assertion, made by a speaker who knows that the antecedent is false, would always violate some Gricean maxims, since such a speaker is always in a position to assert that the antecedent is false, and if the falsity of the antecedent were asserted and accepted, the conditional assertion would no longer be appropriate (since it requires that what is supposed be compatible with the context set). But it might happen that even when the speaker in fact knows that $A$ is false, the addressee is not prepared to accept that $A$ is false - it might be a point of contention in the conversation, in which case the assertion that the antecedent is false will not be accepted, and that proposition cannot be presupposed (by the speaker) without begging the question. In such a case, even though the speaker knows that the antecedent is false, she may have well-grounded conditional beliefs - well-grounded belief revision policies - which might constrain her conditional assertions.

${ }^{15}$ There will always be general Gricean norms of cooperative speech, constraining both categorical and conditional assertions, but these will not be norms that are specific to a kind of speech act, but general constraints on rational cooperative behavior. As Grice noted, it is normally misleading to assert a (material) conditional on the basis of knowledge of the falsity of the antecedent, and he offered an explanation for this in terms of general conversational maxims. Similar explanations could be given by a defender of the conditional assertion account for why it would normally be inappropriate to make a conditional commitment on the basis of knowledge that the condition will remain unfulfilled. 
For example, I take myself (correctly, let us assume) to know that Shakespeare wrote Hamlet. O'Leary, however, disputes it. It is common ground between O'Leary and me that the play was written by someone, and I take myself to know that it was, even conditional on the hypothesis that Shakespeare was not the author. Partly in the interest of ultimately convincing him that I am right about who wrote Hamlet, I might engage in debate with O'Leary about who the author of the play was or could have been if it wasn't Shakespeare. ("Well, we can rule out Christopher Marlowe for the following reasons ...”). It makes sense to talk about conditional belief, conditional on hypotheses that are not only counterfactual, but contrary to the subject's knowledge. Can we also make sense of conditional knowledge in such cases? And if we can, should cases of conditional knowledge be reduced to cases of categorical knowledge of some kind of conditional proposition? Perhaps, but it is clear that it would be wrong to identify the relevant proposition with the corresponding counterfactual proposition. For while I take myself to know that even if Shakespeare didn't write Hamlet, someone did, I also take myself to know that if Shakespeare hadn't written Hamlet, that play would never have been written. ${ }^{16}$ We will return to the issue of conditional knowledge after putting our proposition-expressing hypothesis on the table.

(3) The commitment-to-defend hypothesis for the norm of categorical assertion suggests the following extension to a norm of conditional assertion: In the case of conditional assertions, one undertakes a commitment to defend the truth of the consequent against reasonable challenges, but only with one additional resource available to support it: the proposition expressed in the antecedent. This resource is not itself subject to challenge - the defense is conditional on it.

This account of a norm of conditional assertion also seems to yield the result that a conditional assertion is essentially the same, in the way it is assessed, as the categorical assertion of a material conditional. For if one could defend a material conditional against reasonable challenges, then one could use modus ponens to defend the consequent, with the additional help of the antecedent. And if one could defend the consequent with the help of the antecedent, then by a division of cases, one could defend the material conditional without the help of the antecedent.

(4) Finally, the Bayesian account of assertability suggests a natural extension to an account of conditional assertability, an account that has been one of the primary motivations for the development and defense of the non-propositional account of conditionals. If ordinary assertion goes by degree of belief, then conditional assertion goes by conditional degree of belief. Here, as proponents of the Bayesian account emphasize, we get a divergence between conditional assertability and the assertability of the material conditional, since the probability of a material conditional might be high (because of the low probability of the antecedent) when the conditional probability of consequent on antecedent is low (because the probability of the conjunction of the antecedent and consequent is much lower than the probability of the

\footnotetext{
${ }^{16}$ Examples of this kind were first given by Ernest Adams. The Shakespeare example is from Jonathan Bennett.
} 
antecedent.)

This completes our survey of the alternative accounts of norms of conditional assertion. We will look back at them after sketching a truth-conditional account that treats conditional propositions as propositions that are stronger than the material conditional.

\section{Conditional propositions}

The propositional account I will sketch is the one given in my 1975 paper, "Indicative Conditionals." 17 The account is very simple, and has two components: first, a standard possible worlds and selection-function semantics for the conditional; second, a pragmatic constraint on the selection function that applies only to the case of indicative conditionals. The abstract semantics postulates a set of possible worlds and a selection function, $\mathrm{f}$, taking a possible world $\exists$ and a proposition $A$ into a possible world, $f(A, \exists)$. Propositions are represented by subsets of the set of possible worlds. The semantic rule for the conditional is this:

$A>B$ is true in possible world $\exists$ if and only if $B$ is true in $f(A, \exists)$.

The abstract semantics imposes a number of constraints on the selection function, motivated by the idea that the selection possible world should be a world in which the antecedent proposition is true, but that is otherwise minimally different from the base world from which it is selected. These constraints are common to conditionals of both kinds - indicative and subjunctive.

As we have noted, the pragmatic framework that provides the setting for an account of the effect of speech acts assumes that assertions occur in a context, which determines a set of possible worlds - the context set that represents the live options among which speaker and addressee intend to distinguish between in their conversation. Propositions true in all of the worlds in the context set are (pragmatically) presupposed by the speaker. They include the information that is available, or that the speaker takes to be available, for the interpretation of utterances that occur in the discourse. If the language used is, in any way context-dependent, then the speaker will be assuming that the features of the context on which interpretation depends will be available, which requires that they be presupposed, which is to say that the information is entailed by the context set.

The second component of the account of indicative conditional propositions, a pragmatic constraint on selection function that determines the interpretation of conditionals, is as follows:

If $A$ is compatible with the context set, $\mathbf{C}$, then if $\exists 0 \mathbf{C}, \mathrm{f}(A, \exists) 0 \mathbf{C}$.

In the account of conditional assertion sketched above, we said that a supposition creates a derived context. There will also be a derived context on the propositional account (for both

\footnotetext{
${ }^{17}$ Reprinted as chapter 3 of Stalnaker (1999).
} 
indicative and subjunctive conditionals). The derived context, $\mathbf{C}(A)$ for conditional supposition, A made in context $\mathbf{C}$, will be defined as follows: $\mathbf{C}(A)=\{\mathrm{f}(A, \exists): \exists 0 \mathbf{C}\}$. The effect of the pragmatic constraint is to ensure that in the case of indicative conditionals, the derived context set is a subset of the basic context set. Intuitively, this means that all the presuppositions of the basic context will be preserved in the derived context (assuming this is possible, which it will be provided that the supposition is compatible with the basic context set). The pragmatic constraint is motivated by the hypothesis that the role of the special morphology (the combination of tense, aspect and mood that distinguishes "If pigs could fly, they would have wings" from "If pigs can fly, they have wings," and that we have gotten into the habit of calling "subjunctive”) is to signal that some of the presuppositions of the basic context are being suspended in the derived context. The idea is that the default assumption is that presuppositions of a basic context carry over to the derived context created by the supposition. In the absence of indication to the contrary, the pragmatic constraint will hold. ${ }^{18}$

The combination of the selection function semantics with the pragmatic constraint on selection functions yields an overall account of indicative conditionals that reconciles the thesis that the proposition expressed by a conditional is stronger than the material conditional with the fact that the acceptance of the material conditional seems to be sufficient for the acceptance of the corresponding indicative conditional (at least in contexts in which the negation of the antecedent was not accepted). Once a disjunction of the form (not-A or $B$ ) is accepted in a context (becomes part of the common ground), then the pragmatic constraint on the selection function ensures that the corresponding indicative conditional, (if $A$, then $B$ ), will be true in all of the possible worlds in the context set, and so it will be accepted as part of the common ground that the indicative conditional is true. Dorothy Edgington, in an influential general critique of truth-conditional analyses of conditionals, used the prima facie conflict between this thesis about conditional propositions (that they entail, but are not entailed by, the corresponding material conditional) and this fact about the acceptance conditions for indicative conditionals (that acceptance of the material conditional is sufficient for the acceptance of the indicative conditional) to argue against the thesis. She acknowledged that the account I had developed provided a way around her criticism, but she argued that it did so at too high a cost, the cost of making indicative

${ }^{18}$ On this theory, both kinds of conditionals ( "subjunctive" and "indicative") have the same abstract semantics, but a context-dependent parameter of the interpretation - the selection function - is differently constrained by the different grammatical constructions. So, on this theory, the difference between the two kinds of conditionals is a semantic difference in two different senses, but a purely pragmatic difference in a third sense. The difference is semantic, first in the sense that there will normally be a difference in the proposition expressed by the contrasting conditional sentences, even when uttered in similar situations. And it is semantic also in the sense that the difference is marked by a conventional linguistic device (the tense/aspect/mood difference). But the distinction is pragmatic in that the device works by the way it constrains features of the context. The semantic rule that gives the truth conditions of the conditional as a function of the contextual parameter will be the same for both kinds of conditionals. 
conditionals unacceptably context-sensitive. Her criticisms of my account do point to real problems, but in detail, they are off the mark, missing two distinctions that are important, whatever the ultimate fate of the truth-conditional analysis.

Edgington claims that this analysis gets acceptance conditions right only "by making 'truth' and 'truth conditions' radically information-dependent." Specifically, she claims, "If one party is certain that if $A, B$, and another is not (but regards $A$ as possible), they cannot be disagreeing about the obtaining of the same truth conditions. They must be equivocating. For the former's context set must rule out $A \& \sim B$, and the latter's must not." But this is not correct; it confuses the context set (which, in a non-defective context is the same for speaker and addressee) with the beliefs of the speaker and addressee (which will always be different, if they have any reason to communicate with each other). The pragmatic constraint applies only to the context set - the common ground, which in a non-defective case, coincides with the possible situations compatible with what is presupposed. Even if one party is certain that if $A$, then $B$, if the other is not, and if it is recognized by both that at least one party to the conversation is not in a position to exclude the possibility that $(A \& \sim B)$, then it will not be presupposed by either party that if $A$, then $B$ (or that $\sim(A \& \sim B)$ ). The two may still understand the conditional in the same way.

Edgington may reply that one cannot fully reconcile the truth-conditional account with the phenomena about the acceptance conditions for indicative conditionals unless one extends the pragmatic constraint so that it applies to the private beliefs of speakers as well as to the common ground. The fact she appeals to is that all one needs to know in order to be in a position to make a conditional assertion (in a situation in which one is uncertain whether the antecedent is true) is that the material conditional is true. To account for this fact, on the assumption that the conditional expresses a proposition with a selection-function semantics, one must assume that the speaker's selection function will give priority to possible situations compatible with her beliefs, as well as to possible situations compatible with the common ground. But we can accept this extension of the constraint while still denying that speakers with relevantly different beliefs are equivocating or misunderstanding each other. What must be granted is that in some cases, indicative conditionals are implicitly about the speaker's beliefs. We must allow that what I say when I say something of the form "if A, then B" may not be the same as what you would have said, using the same words. But whether one is defending a truth-conditional account or a conditional assertion account, one needs to recognize that indicative conditionals are conveying information about the speaker's epistemic situation. On either kind of account, we should distinguish assertion conditions (conditions under which one is in an epistemic position to make a conditional assertion) from acceptance conditions (conditions under which one in a position to accept a conditional assertion made by someone else.) I may be in a position to assert a conditional while at the same time be prepared to accept one that appears to conflict with it, if asserted by you. ${ }^{19}$

\footnotetext{
${ }^{19}$ Here I am indebted to the editors' comments for helping me to see the issue more clearly.
} 
Once we acknowledge that our indicative conditional statements are in part about our individual epistemic situations, then one thing that needs to be explained is the fact that conditional statements with the same antecedent and contrary consequents that are made by different speakers in the same context seem to conflict with each other. I think that our account of proposition-expressing indicative conditional statements, together with an account of the dynamics of conversation, can account for such conflicts, as well as for cases where one first accepts one conditional, and then asserts one that seems to conflict with it.

What I would have said had I said "if $A$, then $B$ " may be different from what you say with the same words, but once you have said it, the context changes, and if I still am unsure about the truth of the antecedent, I cannot say "if A, then not-B" without disagreeing with you. On the other hand, if I learn from what you say that the antecedent is false, then I may accept the truth of your conditional, while continuing to affirm one that appears to conflict with it. The following example illustrates this phenomenon. You say "one if by land, two if by sea," meaning that if the British are coming by land, there will be one lantern in the tower, and if they are coming by sea, there will be two lanterns in the tower. I accept what you say, and knowing already that there is just one lantern in the tower, I conclude that the British are coming by land. Before, I was in a position to assert "if the British are coming by sea, there is still only one lamp in the tower," and I am still prepared to say this. If the British are coming by sea, then there must have been some mistake about the signal. There is context-shifting and radical informationdependence here, but a truth-conditional account of what is going on can explain the phenomena, and does not have to say that there is equivocation or misunderstanding. ${ }^{20}$

Edgington's second complaint is that the pragmatic constraint requires an anti-realist conception of truth.

If a context set is sufficiently bigoted or bizarre, any old (non-contradictory) conditional can come out 'true': 'If we dance, it will rain tomorrow', for instance. We dance, and the drought continues unabated. Given what we now know, we would not have uttered those words. But the context is different - in its own context, what was said was 'true.'

But this complaint is misguided, equivocating on what is meant by saying that something is true in a context. A context, in the general framework in question, is represented by a set of possible situations - the context set - which encodes the information that speaker and addressees take to be common ground. Context-sensitive utterances will have truth conditions that are sensitive to the context set, so that there are utterance that might have had different truth values (in the actual world) if their contexts had been different. For example, in one context it is common ground that the speaker intended to refer, with "that man" to George W. Bush when she said "that man won the election", while in another context, the speaker uttered the same sentence, but there it is common ground that he intended to refer to John Kerry. One might say that the

${ }^{20}$ The Paul Revere example is discussed briefly in Stalnaker (1984), 108. 
sentence was true in the first context, and false in the second. This is the most straightforward sense of "true in a context". On the other hand, since the context is represented by a set of possible worlds, one might mean by "true in a context" what is true in all of the possible worlds in the context set that represents that context. On this interpretation, to say that something is true in a context is to say that it is presupposed in that context - which is to say that it was taken to be common ground (whether it is actually true or not.) In the second sense, "that man won the election" will be true in both of the above contexts, assuming that the assertion was accepted in both contexts. Truth in a context, in the second sense, is not a special notion of truth, but is just truth with respect to certain nonactual situations.

Edgington's rain dance example is an example of a conditional that is presupposed, and presumably believed, to be true, but that is in fact false. So it is "true in the context" only in the second (somewhat misleading) sense. This is no more a problem for a realist notion of truth than the fact that "John Kerry won the election" is true in possible situations compatible with the beliefs of people who think that he won. The pragmatic constraint on selection functions does imply that the actual truth of a conditional will sometimes be context-sensitive, but only when the actual world is compatible with the context, since it constrains the truth-conditions of the conditionals only in the possible worlds in the context set - those compatible with what is presupposed. ${ }^{21}$ The constraint has no consequences for the truth-conditions of conditionals in possible worlds outside the context set, including the actual world, should that world be incompatible with what is presupposed. ${ }^{22}$ But while the pragmatic constraint is not relevant to the actual truth value of the conditional in Edgington's example, the abstract semantics requires that it be false with respect to any context, since the antecedent is true, and the consequent false.

So this truth-conditional account of indicative conditionals is not quite so quickly refuted as Edgington thought, and does not require any kind of nonstandard conception of truth. No truthconditional account will have a problem with examples (such as Edgington's rain dance example) with true antecedents. But there are related problems, brought most clearly into focus by Allan Gibbard's famous example of Sly Pete, the Mississippi Riverboat gambler. This is an example of a pair of apparently contrary conditionals with false antecedents, but which are made in a context in which the actual situation is compatible with what is presupposed. Here is Gibbard's story:

Sly Pete and Mr. Stone are playing poker on a Mississippi riverboat. It is now up to Pete to call or fold. My henchman Zack sees Stone's hand, which is quite good, and signals its contents to Pete. My henchman Jack sees both hands and sees that Pete's hand is rather low, so that Stone's is the winning hand. At this

${ }^{21}$ Conditionals will presumably be context-sensitive in some cases, even when the actual world is outside the context set, but my point is that this one specific pragmatic constraint does not imply that they are.

${ }^{22}$ This reply to Edgington criticism is developed in Block (2004) 
point the room is cleared. A few minutes later Zack slips me a note which says 'if Pete called, he won,' and Jack slips me a note which says 'if Pete called, he lost.'. .. I conclude that Pete folded. ${ }^{23}$

Jack and Zack, in this story, each have only partial information about the situation but each recognizes the way in which his information is partial, and neither is making any mistake. So the actual situation is compatible with the beliefs of both henchmen, and we may presume it is also compatible with the contexts in which each communicates with the narrator of the story (Call him “Allan”). So the putative problem for the truth-conditional account is this: Suppose that indicative conditionals express propositions, and that a conditional assertion is the categorical assertion of a conditional proposition. Then it seems that (1) Zack is not in a position to rule out what is in fact the actual situation in which Pete folds with a losing hand, and it does not seem that he is ruling it out. But (2) it seems that he is in a position to assert "if Pete called, he won" (thus ruling out all possible situations incompatible with the truth of the proposition expressed). But then it must be that (3) the conditional proposition expressed is true in the actual situation. Similarly for Jack, with his assertion of an apparently contrary conditional proposition. So it seems that when Jack says, "If Pete called, he lost", he speaks the truth, but also that Zack speak the truth when he says "if Pete called, he won". If we further assume that the conditional sentences are interpreted with a selection-function semantics, then we must assume that the selection function relevant to interpreting Zack's conditional is different from the one relevant to the interpretation of Jack's. To explain the truth and assertability of the conditionals, each selection function must be constrained, not only by the presumed knowledge that they share - the common ground - but also by their private beliefs or knowledge. But the information necessary to interpret a context-sensitive expression is supposed to be presumed by the speaker to be available to the addressee, and so to be presupposed. In general, a speaker's private beliefs and knowledge may be expressed in his assertions, but where they are not common ground, they cannot be presumed to be available for the interpretation of what is expressed.

But as we have seen, there is no conflict between the assumption that the selection function for interpreting conditional propositions is constrained by a speaker's private beliefs and the assumption that the relevant selection function must be public knowledge. As I suggested above, in discussing Edgington's first objection, the assumption that the selection function is constrained by the speaker's private beliefs does imply that a conditional in one speaker's mouth may say something different from what would have been said by a different speaker, in the same context, with the same conditional sentence. But it does not imply that the information necessary to interpret each speaker's conditional is not publicly available. For if it is a general constraint that selection functions for indicative conditionals should, where possible be closed under the speaker's knowledge or beliefs, then it will be common ground that this constraint will hold. Even if the addressee does not know what the speaker knows, he will know, and it will be common ground, that the world selected from a given possible world in the context set will be constrained by what the speaker knows or believes in that possible world

${ }^{23}$ Gibbard (1981), 231. 
Let me spell the point out in detail, in terms of the riverboat example ${ }^{24}$ : Let $\forall, \exists$ and ( be three possible worlds in which Pete in fact folded. $\forall$ is the actual world in which Jack knows that Pete had a losing hand. $\exists$ is a possible world in which Jack knows that Pete had a winning hand, and (is a possible world in which Jack does not know whether Pete has a winning or a losing hand. Let $\mathrm{f}_{\mathrm{J}}$ be the selection function relevant to interpreting Jack's conditional statements, let $P$ be the proposition that Pete called, and let $L$ be the proposition that he lost. Possible worlds of the three kinds ( $\forall, \exists$ and () are compatible with the knowledge of Allan, the narrator, and with the context in which Jack's message is passed to Allan. But even though Allan does not know, and Jack does not presuppose, that the actual world is $\forall$, rather than $\exists$ or (, Allen does know, and it is common ground, that $\mathrm{f}_{\mathrm{J}}(P, \forall)$ is a possible world in which $L$ is true, and that $\mathrm{f}_{\mathrm{J}}(P, \exists)$ is a possible world in which $L$ is false. (Nothing is implied by the constraints we are considering about $\mathrm{f}_{\mathrm{J}}(P,()$.) When Allan receives Jack's message, he understands it, and when he accepts it, he rules out possible world $\exists$. (He also, of course, rules out possible worlds in which Pete called and won.)

What about possible worlds like (? Suppose that, in (, Jack does not know anything that gives him reason to exclude either the possibility that Pete called and won, or the possibility that Pete called and lost. Then nothing we have said implies that the literal content of Jack's conditional statement is true, or that it is false, but Allan will still be able to exclude that possibility on the ground that Jack would not be in a position to assert the conditional if world ( were actual.

Even though Jack would not have made the conditional statement if world ( were actual, we still might ask whether (on the truth-conditional account) the conditional proposition he expressed (in $\forall$ ) was true or false in (. It seems intuitively clear that the corresponding counterfactual conditional proposition, "if Pete had called, he would have lost" will be true (whatever Jack knew or believed) just in case Pete had a losing hand, but what about the indicative conditional? Here, the most natural intuitive judgment may be that the question does not arise - no nonarbitrary truth value can be assigned. This may seem to lend support to the conditional assertion account, according to which nothing has been asserted when the antecedent is false, but a proponent of the truth-conditional account might say the same thing, allowing (as seems plausible for both counterfactual and indicative conditionals) that selection functions may sometimes be only partially defined. A cautious version of the kind of truth-conditional account of indicative conditionals that I have been promoting might hold that, with indicative conditionals, all selection functions compatible with the epistemic and contextual constraints are

${ }^{24}$ In Gibbard's telling of the story, he adds that Allan knows that the notes come from his trusted henchmen, but doesn't know which note came from which (and so presumably does not know anything about the basis for their conditional claims.) To simplify the analysis (avoiding a proliferation of alternatives), I assume that Allan knows that the note came from Jack, and something about Jack's epistemic situation. I don't think anything essential is lost by this simplification of the story. 
admissible, and that indicative conditionals are true if and only if true with respect to all admissible selection functions, and false if and only if false for all. This version of the truthconditional account will be essentially equivalent to a version of the conditional assertion account. One may not have to choose; it may be that one can have some of the advantages of both. One advantage, in particular, to bringing the truth-conditional and conditional assertion accounts together is that it may facilitate a more unified theory of conditionals, and an explanation of the relations between indicative and "subjunctive" conditionals.

To account for the phenomena, we must assume, as Edgington noted, that conditionals are information-sensitive, both to public and private information. The pragmatic constraint imposed in my original account of indicative conditionals concerned only the relation between common ground - publicly available information - and the interpretation of conditionals. The aim there was limited to an explanation of the force of a certain argument, and more generally, to an exploration of one case of the interaction of context and content in the dynamics of discourse. But the Gibbard example, and others, make clear that indicative conditionals, if they are given a truth-conditional account, will be sensitive also to the knowledge or beliefs of individual speakers and thinkers, and so to information that is not, in general, publicly available. This kind of speaker-relativity means that indicative conditionals are, implicitly, in part about the speaker's epistemic situation, but this does not require any non-standard notion of proposition, or of truth, and it does not imply that speakers and addressees who are ignorant of each other's private beliefs do not understand each other.

The two kinds of constraints on the interpretation of indicative conditionals (by the common ground, and by the speaker's individual epistemic situation) will interact, and there will in some cases be tensions between them. I will conclude by considering an example that illustrates one such tension - an example that raises a problem for both truth-conditional and conditional assertion accounts. I am not sure what to say about this example, but will make a tentative suggestion.

\section{Public vs. private information}

There are only three possible suspects for the murder - the butler, the gardener, and the chauffeur - and it is common knowledge that whoever did it acted alone. Alice was with the gardener at the time of the murder, so she is absolutely certain that he is innocent. Bert has conclusive evidence that rules out the chauffeur, which he has shared with Alice, so it is common knowledge between Alice and Bert that either the butler or the gardener did it. Alice concludes (privately) that since it wasn't the gardener, it must have been the butler. But Bert has what is in fact misleading evidence that he takes to exonerate the butler, so he infers that it must have been the gardener. Alice and Bert each tell the other who he or she believes was the guilty party, but neither is convinced by the other. Alice, in particular, is far more certain of the innocence of the gardener than she is of the guilt of the butler; were she to learn, to her surprise, that the butler was innocent, she would conclude that the chauffeur's alibi must not be as good as it looks, and that he is the guilty party. But that won't happen, since in fact, the butler did it. 
Bert says, "We disagree about who did it, but we agree - it is common knowledge between us that either the butler or the gardener did it, and each possibility is compatible with our common knowledge. So even though you are convinced that the butler is the guilty party, you should agree that if the butler didn’t do it, the gardener did.” Bert is just giving what I have called the direct argument, which all of the accounts on the table have assumed to be compelling.

Alice agrees that it is common knowledge that either the butler or the gardener did it, and that each of the two possibilities is compatible with their common knowledge. But she will be reluctant to accept the conditional, which conflicts with her conditional belief - perhaps with her conditional knowledge - that even if the butler didn't do it, the guilty party is still not the gardener.

If, in this case, we assume that common knowledge (what Alice and Bob both know, know that they know, know that they know that they know, etc.) coincides with the common ground (the context set), then if Alice reasonably refuses to accept Bert's conditional conclusion ("if the butler didn't do it, the gardener did"), we have a counterexample to the pragmatic constraint imposed in my original truth-conditional account of indicative conditionals. The example also seems to conflict with our conditional assertion account, which implies that one should accept $B$, conditional on $A$, if $A$, added to the common ground, entails $B$. But on the other hand, if Alice accepts the conditional that Bert invites her to accept, she will be apparently violating a conditional knowledge norm, and (from the point of view of the Bayesian account of assertability) asserting something unassertable. ${ }^{25}$ On the truth-conditional analysis, what we seem to have is a case where the requirement to select a possible world from the context set conflicts with the requirement to select a possible world from the set of possibilities compatible with the individual's conditional knowledge

I am not sure what the best response to this problem is, but I am inclined to think that one should question the assumption that everything that is common knowledge is common ground. That is, I am inclined to think that some possible situations that are incompatible with the common knowledge of the parties to a conversation are nevertheless "live options" in that conversation. When it becomes clear that the guilt of the butler is in dispute, so that it is a live option in the context that butler didn't do it, Alice should insist that we reopen the possibility that the guilty party was the chauffeur. ("I am sure it was the butler, but if it wasn't the butler, it might have been the chauffeur.") The context set should be expanded to include possibilities compatible with the conditional knowledge of the parties on any condition compatible with the context. This would be a way of reconciling the conflicting constraints, and seems to be intuitively plausible.

${ }^{25}$ I assume that in an appropriate Bayesian account, conditional probabilities may be defined even when the probability of the condition is 0 . Such conditional probabilities represent conditional degrees of belief, on conditions that are entertainable, even though they are taken to be certainly false. Alice is disposed, should she be surprised by the information that the Butler was certainly innocent, to revise her beliefs so that she would still assign very low credence, relative to that condition, to the proposition that the gardener did it. 
The riverboat example was an example of the pooling of information. The different parties knew different things, but had no disagreements. The murder example is a case where the different parties know what each other thinks, but they disagree, so their beliefs continue to diverge. This kind of case may require a more complex account of the common ground. ${ }^{27}$

${ }^{26}$ Thony Gillies pointed out that, if we expand the context set in this way, then Bert could attempt to close it again simply by asserting the disjunction, "either the butler or the gardener did it." Alice, it might seem, should accept this disjunctive assertion, since its content is entailed by something she accepts. But the response I am tentatively proposing must say that Alice should reject the assertion, despite the fact that it is entailed by something she believes. Given that her assertion that the butler did it was rejected, she should not be willing to accept this particular weakening of her assertion. "If we can't agree that the butler did it, we also can't agree that it was either the butler or the gardener." It is surprising that one might reasonably reject an assertion even if one would assert or accept one that entails it, but this still may be the right response. Compare Grice's discussion of what he calls "substitutive disagreement”, where one rejects a disjunctive statement, "either Wilson or Heath will be the next Prime Minister" in favor of another that shares one of the disjunctions ("I disagree, it will be either Wilson or Thorpe.”). Grice(1989), 64.

${ }^{27}$ Thanks to Thony Gillies, Isadora Stojanovic, Andy Egan, and the editors of New work on modality (where this paper was originally published) for extremely helpful comments on versions of this paper. Thanks also to Jonathan Bennett for conversation and correspondence over the years about conditionals that helped me to get clearer about many issues. 


\section{References}

Block, E. "Conditionals in context” (ms.)

Brandom, R. (1983) “Asserting”, Nous 17, 637-50.

Edgington, D.(1986) “Do conditionals have truth conditions?” Critica 18, 3-30. Reprinted in Jackson (1991), 176-201. Page references to the reprinted version.

Edgington, D.(1995) “On conditionals”. Mind, 104, 235-329..

Gibbard, A. (1981). “Two recent theories of conditionals”. Ifs: Conditionals, Belief, Decision, Chance and Time (ed. by W. L. Harper, R. Stalnaker, and G. Pearce).. DordrechtHolland: D. Reidel, 211-47.

Grice, P. (1989). Studies in the Way of Words. Cambridge, MA: Harvard University Press.

Lewis, D. (1976) “Probabilities of conditionals and conditional probabilities” Philosophical Review, 85, 297-315.

Lewis, D. (1979). “Scorekeeping in a language game” Journal of Philosophical Logic 8, 339-59.

Mackie, J. L.((1973) Truth, Probability and Paradox. Oxford: Clarendon Press.

New Work on Modality (MIT Working Papers in Linguistics and Philosophy, 51, 2005)

Quine, W. V.(1959) Methods of Logic (revised edition) New York: Holt, Rinehart and Winston.

Stalnaker, R. (1984) Inquiry. Cambridge, MA: MIT Press.

Stalnaker, R. (1999) Context and Content. Oxford: Oxford University Press.

Swanson, E. (2004) “A suppositional theory of conditionals” (ms.)

von Wright, G. H.. (1957) Logical Studies. New York: The Humanities Press.

Williamson, T. (1996) “Knowing and asserting”, Philosophical Review, 105, 489-523.

Williamson, T. (2000) Knowledge and its Limits. Oxford: Oxford University Press. 